\title{
Effect of Retail Clinic Use on Continuity of Care Among Medicare Beneficiaries
}

\author{
N. Ogechi Abara, MD, Nicole Huang, BSc, Mukaila A. Raji, MD, \\ and Yong-Fang Kuo, PhD
}

Purpose: We examined the relationship between retail clinic use and primary care physician (PCP) continuity among Medicare enrollees in the Houston metropolitan area.

Methods: We identified retail clinic providers in the study area using a 2015 health care provider database. Medicare claims data from enrollees who received care from retail clinics in 2015 were compared with propensity score-matched sample of enrollees who received no care from retail clinics.

Results: There were 2.32 retail clinic visits per 1000 beneficiaries in a month. Approximately $1.3 \%$ of Medicare beneficiaries used retail clinics. Retail clinic users were more likely to be aged 65 to 74 years, female, White, and Medicaid ineligible. In multivariable analyses with adjustments for covariates, significant predictors of retail clinic use included having $\geq 3$ chronic conditions (Odds Ratio [OR], 1.53 vs no condition), living within 1 mile of a retail clinic (OR, 2.44 vs living $\geq 5$ miles), and having no PCP (OR, 1.11 vs having PCP). Compared with propensity-matched controls, among enrollees with an identified PCP, likelihood of seeing their PCP (OR, $0.82 ; 95 \%$ CI, 0.73 to 0.93$)$ and continuity of care was lower $(0.75 \pm 0.33$ vs $0.80 \pm 0.31)$ if they had retail clinic visits.

Conclusions: Retail clinic use was lower in the elderly population compared with the previously published rate in the younger populations. The lower rate of continuity of care observed among retail clinic users is concerning, especially for those with chronic medical conditions. (J Am Board Fam Med 2019; 32:531-538.)

Keywords: Ambulatory Care, Chronic Disease, Medicare, Continuity of Patient Care, Patient-Centered Care, Primary Care Physicians, Primary Health Care, Retail Clinic, Nurse Practitioner

Retail clinics, first established in the United States in $2000,{ }^{1}$ have by 2017 expanded to over 1960 US locations. ${ }^{2}$ Retail clinics represent a shift from tra-

This article was externally peer reviewed.

Submitted 22 November 2018; revised 10 February 2019; accepted 11 February 2019.

From the Department of Internal Medicine, Division of Geriatrics (NOA, MAR), Sealy Center on Aging (MAR, YFK), School of Medicine (NH), and Department of Preventive Medicine and Community Health, University of Texas Medical Branch, Galveston, TX (MAR, YFK).

Funding: This work was supported by Grants R01HS020642 from the Agency for Healthcare Research and Quality, P30-AG024832 from the National Institute on Aging, and UL1-TR001439 from the National Center for Advancing Translational Sciences, National Institutes of Health. The funders had no role in the design and conduct of study; the collection, management, analysis, and interpretation of the data; or the preparation, review, or approval of the manuscript.

Conflict of interest: none declared.

Corresponding author: Yong-Fang Kuo, PhD, Department of Preventive Medicine and Community Health, University of Texas Medical Branch, 301 University Boulevard, Galveston, TX 77555-0177 (E-mail: yokuo@utmb.edu). ditional care delivery, being staffed mostly by nurse practitioners (NPs) and physician assistants (PAs) and located within retail stores. ${ }^{1}$ The clinics offer basic primary and acute care, such as vaccinations and treatment for mild acute conditions. ${ }^{3}$ Advantages of the retail clinic system include walk-in care and after-hour/weekend care. ${ }^{4,5}$ About $44 \%$ of all retail clinic visits occur when traditional primary care physicians' offices are closed. ${ }^{4}$ These clinics accept a large percentage of insurances and visits may cost less than at a traditional primary care physician's office. ${ }^{6}$ It is therefore not surprising that retail clinic use is growing quickly especially among the commercially insured working age population. ${ }^{7}$ This growth is likely to continue, given the recent expansion of multinational retail/pharmacy chains (eg, recent CVS/Aetna merger) into retail clinic business. ${ }^{8,9}$

While data exist on trends and outcomes of retail clinic use among the younger population and 
the commercially insured, ${ }^{3,7,10-11}$ little is known about retail clinic use among elderly Medicare beneficiaries. This population often has multiple coexisting chronic diseases (eg, congestive heart failure and diabetes mellitus) that require coordination and integration of care across many providers and health care settings. The extent of care coordination/integration between the retail clinic providers and the patient's primary care physician (PCP) is not clear. Continuity of primary care is particularly important for the elderly because of its association with fewer hospital/emergency room (ER) visits and lower health care costs. ${ }^{12}$

Several questions remain regarding retail clinic use by older Medicare beneficiaries. What is the profile of seniors who visit retail clinic for acute and chronic care? What proportion of seniors' retail clinic visit is for chronic disease management (CDM)? Is there any relationship between retail clinic use and continuity of care with the patient usual primary care physician? Answering these questions can guide policy makers, clinicians, health care payers, and health system leaders when developing changes to improve care among older retail clinic users.

The purposes of this study are to examine the geographic distribution and type of retail clinic providers (NP, PA, vs MD) in Houston metropolitan area, the sociodemographic and health characteristics associated with retail clinic use, and the relationship between retail clinic use and continuity of care.

\section{Methods}

\section{Source of Data}

We used the $100 \%$ Texas Medicare Claims (20142015), including Medicare beneficiary summary files, Medicare Provider Analysis and Review (MedPAR) files, Outpatient Standard Analytic Files, and Medicare Carrier files. Health care providers including physicians, NPs and PAs who practiced in retail clinics in the Houston Metropolitan area in 2015 were identified through a health care provider database from IMS Health. This database was generated primarily from National Provider Identifier (NPI) files, medical boards, state licensing, Drug Enforcement Administration (DEA), and provider directory from insurance companies. It includes provider NPI, practice identifier, practice name and address. We searched practice name for RediClinic, MinuteClinic, Health care Clinic, Walmart Care Clinic, Target Clinic, and The Little Clinic to identify health care providers with a primary practice location in retail clinics.

\section{Study Coborts}

We selected Medicare beneficiaries residing in 9 counties of the Houston metropolitan area. Only those with Parts A and B coverage and not in a health maintenance organization (HMO) in 2015 were included ( $\mathrm{n}=366,225)$. Among these beneficiaries, 4706 had at least 1 retail clinic visit in 2015. To assess patients' chronic disease conditions, previous continuity of care, and whether they had an identified PCP, the study cohort was further restricted to those who had Part A and B coverage and were not in an HMO in 2014 as well $(\mathrm{n}=$ 322,994 including 4105 enrollees with retail clinic visits). Therefore, this cohort represents beneficiaries with continuous coverage in 2014 and 2015, allowing for analysis of beneficiaries' comorbidities, evidence of a PCP before the retail clinic visit in study year of 2015 and continuity of care.

\section{Patient Characteristics}

Medicare enrollment files provided information on patient age, gender, and race/ethnicity. We used a Medicaid indicator in the enrollment file as proxy for low income. We defined and classified 15 chronic conditions according to the classification scheme developed by the Department of Health and Human Services. ${ }^{13}$ Chronic conditions, number of hospitalizations, and number of provider visits were generated from the claims in 2014. We then assigned each patient to a PCP. We defined a PCP as a generalist (general practitioner, family physician, internist or geriatrician) who saw a given beneficiary on 2 or more occasions in an outpatient setting in $2014 .{ }^{14}$ If more than 1 PCP met criteria, the 1 who saw the beneficiary most often was assigned. If more than 1 PCP saw the beneficiary with the same frequency, the 1 saw the beneficiary most recently was assigned. For patients with at least 2 PCP visits in 2014, the BiceBoxerman Continuity of Care Index (COC) for primary care was calculated. ${ }^{15}$ The distance between the nearest retail clinic and beneficiary's residential zip code was calculated and grouped as $\leq 1$ mile, $>1$ to $\leq 5$ miles, and $>5$ miles.

\section{Study Outcome}

Continuity of care assessed by determining whether beneficiaries had a visit to his/her identified PCP in 2015 , and by their primary care COC in 2015. To 
reduce selection bias between beneficiaries who visited retail clinics and those who did not, we performed propensity score matching. The propensity score of having retail clinic visits was generated using 2 logistic regression models-one for those patients had an identified PCP, and another for those patients without an identified PCP. Patient characteristics including age, gender, race/ethnicity, Medicaid eligibility, number of chronic conditions, hospitalizations and health care provider visits in previous year, and distance to nearest retail clinic were included in each model. For each beneficiary with retail clinic visits, we performed greedy matching to select 3 beneficiaries without retail clinic visits. ${ }^{16}$ For this, a patient with retail clinic visit is first randomly selected. Then 3 patients without a retail clinic visit, each whose propensity score is closest to that of this randomly selected retail clinic patient, are chosen for matching to the retail clinic patient. This process is repeated for each retail clinic patient. Balance of covariates after propensity matching was assessed by standardized difference and by the overlap of propensity score. ${ }^{17}$

\section{Statistical Analyses}

Proportions of beneficiaries with retail clinic visits were calculated by each patient characteristic. The adjusted odds ratio (OR) and 95\% confidence interval (CI) for each patient characteristic associated with retail clinic visit was estimated from a multivariate logistic regression model. For outcomes of study, a conditional logistic regression model was built to examine the association between retail clinic visits and whether patients saw their PCP in the propensity match cohort. All tests of statistical significance were 2-sided and analyses were performed with SAS 9.4 (SAS Inc., Cary, NC).

\section{Results}

Among 126 retail clinic providers ( $75 \% \mathrm{NPs}$ ) in Houston metropolitan area in $2015,56 \%$ were in Harris County and about $12 \%$ in each of the suburban counties including Brazoria, Ford Bend, and Montgomery counties. Most of these providers practiced near the boundary of Harris County. Table 1 demonstrates profiles of retail clinic users in 2015. Overall, $1.3 \%$ of users were Medicare beneficiaries. Retail clinic users were more likely to be female, White, aged 65 to 74 years of age, and
Medicaid ineligible. In the multivariable analyses, residents within 1 mile of the nearest retail clinic had nearly 2.5 times higher odds of using a retail clinic as those residing more than 5 miles away (OR, 2.47; 95\% CI, 2.09 to 2.92). Patients without chronic conditions had lower odds of visiting retail clinics (OR, 0.70; 95\% CI, 0.63 to 0.77 ) compared with those with 1 chronic condition). Medicare beneficiaries who had an identified PCP had lower odds of visiting a retail clinic in 2015 (OR, 0.9; 95\% CI, 0.84 to 0.97). Seventyone percent of patients with an identified PCP had only 1 PCP. Their COC index was much higher than those without an identified PCP $(0.84 \pm 0.26$ vs $0.004 \pm 0.059)$.

On a monthly basis in 2015, there were 2.32 retail clinic visits versus 242 PCP visits made per 1000 beneficiaries. About 24\% of patients who went to retail clinics had received care over the weekend. The commonest reason for retail clinic was for vaccination $(24.2 \%$ of total retail clinic visits), mostly against Influenza. When analyzed based on acuity and complexity, $36.8 \%$ were visits for simple acute conditions such as urinary tract infection, acute sinusitis, otitis media, allergic rhinitis, pneumonia, respiratory infection, and skin conditions. Chronic conditions (including congestive heart failure, hypertension, diabetes and chronic obstructive pulmonary disease), and preventive care accounted for about $13 \%$ of retail clinic visits $(10 \%$ and $2.7 \%$ of visits, respectively).

As shown in Table 2, propensity score match analyses balanced baseline covariates between patients with and without retail clinic visits for both patients with an identified PCP and for patients without an identified PCP. Propensity scores between the 2 groups completely overlapped. However, the proportion of patients with a retail clinic visit who failed to see their PCP in 2015 was greater than that for those without visits to retail clinics $(21.4 \%$ vs $18.3 \%)$. From the conditional logistic regression model, among beneficiaries with an identified PCP, the odds of seeing their PCP decreased if they had retail clinic visits (OR, 0.82; $95 \%$ CI, 0.73 to 0.93$)$. We also found average COC indices in 2015 were lower in beneficiaries who used retail clinics, regardless of whether patients had an identified PCP or not $(0.75 \pm 0.33$ vs $0.80 \pm 0.31, P<.001$, and $0.64 \pm 0.40$ vs $0.74 \pm$ $0.37, P<.001)$. 
Table 1. Characteristics Associated with Retail Clinic Visits in the Entire Study Cohort

\begin{tabular}{|c|c|c|c|c|c|}
\hline Characteristic & $\begin{array}{c}\text { Houston Metro Medicare } \\
\text { Population }\end{array}$ & $\begin{array}{c}\text { Retail Clinic Medicare } \\
\text { Population }\end{array}$ & $\begin{array}{l}\text { Retail Clinic } \\
\text { Visit, \% }\end{array}$ & $\mathrm{OR}^{\ddagger}$ & $95 \% \mathrm{CI}$ \\
\hline Overall & 366,225 & 4706 & 1.29 & & \\
\hline \multicolumn{6}{|l|}{ Age (years) } \\
\hline$<65$ & 51,465 & 445 & 0.86 & 0.78 & 0.68 to 0.89 \\
\hline $65-69$ & 91,420 & 1196 & 1.31 & 1.00 & \\
\hline $70-74$ & 80,721 & 1132 & 1.40 & 1.01 & 0.92 to 1.10 \\
\hline $75-79$ & 55,902 & 751 & 1.34 & 0.90 & 0.82 to 1.00 \\
\hline $80-84$ & 40,413 & 534 & 1.33 & 0.83 & 0.74 to 0.93 \\
\hline$\geq 85$ & 46,934 & 648 & 1.40 & 0.84 & 0.75 to 0.93 \\
\hline Mean $\pm \mathrm{SD}$ & $71.89 \pm 11.77$ & $73.27 \pm 10.24$ & & & \\
\hline Median (Q1, Q3) & $72(67,79)$ & $73(68,80)$ & & & \\
\hline \multicolumn{6}{|l|}{ Sex } \\
\hline Male & 166,663 & 1804 & 1.08 & 1.00 & \\
\hline Female & 199,562 & 2902 & 1.45 & 1.29 & 1.21 to 1.38 \\
\hline \multicolumn{6}{|l|}{ Race/Ethnicity } \\
\hline White & 249,980 & 3795 & 1.52 & 1.74 & 1.55 to 1.95 \\
\hline Black & 53,445 & 418 & 0.78 & 1.00 & \\
\hline Hispanic & 41,938 & 284 & 0.68 & 0.92 & 0.78 to 1.09 \\
\hline Other & 20,862 & 209 & 1.00 & 1.15 & 0.95 to 1.40 \\
\hline \multicolumn{6}{|l|}{ Medicaid Eligibility* } \\
\hline Yes & 47,679 & 405 & 0.85 & 1.00 & \\
\hline No & 318,546 & 4301 & 1.35 & 1.26 & 1.12 to 1.43 \\
\hline \multicolumn{6}{|c|}{ Distance to nearest retail clinic } \\
\hline$\leq 1$ mile & 164,806 & 2663 & 1.62 & 2.47 & 2.09 to 2.92 \\
\hline$>1$ to $\leq 5$ miles & 174,341 & 1876 & 1.08 & 1.81 & 1.53 to 2.14 \\
\hline$>5$ miles & 27,075 & 167 & 0.62 & 1.00 & \\
\hline \multicolumn{6}{|l|}{ Chronic conditions $^{\dagger}$} \\
\hline 0 & 11,651 & 939 & 0.84 & 0.70 & $0.63-0.77$ \\
\hline 1 & 47,152 & 639 & 1.36 & 1.00 & \\
\hline 2 & 50,063 & 691 & 1.38 & 1.01 & 0.90 to 1.12 \\
\hline $3+$ & 114,128 & 1836 & 1.61 & 1.06 & 0.96 to 1.17 \\
\hline \multicolumn{6}{|c|}{ Hospitalization in $2014^{\dagger}$} \\
\hline 0 & 271,556 & 3159 & 1.16 & 1.00 & \\
\hline 1 & 34,292 & 608 & 1.77 & 1.22 & 1.11 to 1.34 \\
\hline 2 & 9930 & 186 & 1.87 & 1.22 & 1.05 to 1.43 \\
\hline $3+$ & 7216 & 152 & 2.11 & 1.41 & 1.19 to 1.68 \\
\hline \multicolumn{6}{|l|}{ Provider visit in $2014^{\dagger}$} \\
\hline Mean \pm SD & $7.75 \pm 7.64$ & $10.34 \pm 8.93$ & & 1.02 & 1.02 to 1.03 \\
\hline Median (Q1, Q3) & $6(2,11)$ & $8(4,14)$ & & & \\
\hline \multicolumn{6}{|c|}{$\begin{array}{l}\text { Having an identified primary } \\
\text { care physician in } 2014^{+}\end{array}$} \\
\hline Yes & 163,972 & 2356 & 1.44 & 0.90 & 0.84 to 0.97 \\
\hline No & 159,022 & 1749 & 1.10 & 1.00 & \\
\hline
\end{tabular}

*To be eligible for Medicaid, individuals must meet financial criteria based on taxable income and tax filing relationships. For those aged 65 years and older, eligibility is determined using income methodologies of the supplemental security income (SSI) program. (Borella M, De Nardi M, French E. Who receives Medicaid in old age? Rules and reality. Fiscal Studies 2018;39:65-93).

${ }^{+}$Beneficiaries with continuous enrollment of Part A and B without HMO in 2014.

${ }^{\ddagger}$ Results from multivariable logistic regression to examine patient characteristics associated with use of retail clinic $(\mathrm{n}=322,994$; those with Medicare Part A and B without HMO in 2014).

OR, odd ratio; CI, confidential interval; SD, standard deviation. 
Table 2. Comparisons Between Patients With Retail Clinic Visits and Patients Without Retail Clinic Visits Matched by Propensity Score

\begin{tabular}{|c|c|c|c|c|c|c|}
\hline & \multicolumn{3}{|c|}{ Patients with an identified PCP in 2014} & \multicolumn{3}{|c|}{ Patients without an identified PCP in 2014} \\
\hline & \multicolumn{3}{|c|}{ Retail Clinic } & \multicolumn{3}{|c|}{ Retail Clinic } \\
\hline & No & $\mathrm{Yes}^{\dagger}$ & $\begin{array}{c}\text { Standardized } \\
\text { Difference (\%) }\end{array}$ & No & Yes $^{\ddagger}$ & $\begin{array}{c}\text { Standardized } \\
\text { Difference (\%) }\end{array}$ \\
\hline $\mathrm{N}$ & 7047 & 2349 & & 5235 & 1745 & \\
\hline \multicolumn{7}{|l|}{ Age, years } \\
\hline$<65$ & $7.4 \%$ & $8.0 \%$ & 2.82 & $9.7 \%$ & $10.2 \%$ & 1.93 \\
\hline $65-69$ & $19.5 \%$ & $19.5 \%$ & & $21.5 \%$ & $21.3 \%$ & \\
\hline $70-74$ & $26.6 \%$ & $26.0 \%$ & & $25.9 \%$ & $26.0 \%$ & \\
\hline $75-79$ & $18.1 \%$ & $18.6 \%$ & & $16.4 \%$ & $16.4 \%$ & \\
\hline $80-84$ & $12.8 \%$ & $12.7 \%$ & & $12.0 \%$ & $11.9 \%$ & \\
\hline$\geq 85$ & $15.6 \%$ & $15.2 \%$ & & $14.5 \%$ & $14.3 \%$ & \\
\hline \multicolumn{7}{|l|}{ Sex } \\
\hline Male & $34.9 \%$ & $35.3 \%$ & 2.02 & $42.4 \%$ & $42.7 \%$ & 1.72 \\
\hline Female & $65.1 \%$ & $64.7 \%$ & & $57.6 \%$ & $57.3 \%$ & \\
\hline \multicolumn{7}{|l|}{ Race/ethnicity } \\
\hline White & $82.3 \%$ & $81.9 \%$ & 1.57 & $82.0 \%$ & $81.4 \%$ & 1.94 \\
\hline Black & $7.9 \%$ & $8.2 \%$ & & $8.9 \%$ & $9.0 \%$ & \\
\hline Hispanic & $6.3 \%$ & $6.2 \%$ & & $5.3 \%$ & $5.7 \%$ & \\
\hline Other & $3.5 \%$ & $3.7 \%$ & & $3.8 \%$ & $3.9 \%$ & \\
\hline \multicolumn{7}{|l|}{ Medicaid eligibility } \\
\hline Yes & $7.2 \%$ & $7.8 \%$ & 2.42 & $9.3 \%$ & $8.8 \%$ & -1.79 \\
\hline No & $92.8 \%$ & $92.2 \%$ & & $90.7 \%$ & $91.2 \%$ & \\
\hline \multicolumn{7}{|l|}{ Distance to nearest retail clinic } \\
\hline$\leq 1$ mile & $55.0 \%$ & $54.4 \%$ & 1.37 & $57.6 \%$ & $57.4 \%$ & 2.27 \\
\hline$>1$ to $\leq 5$ miles & $41.8 \%$ & $42.3 \%$ & & $38.7 \%$ & $38.4 \%$ & \\
\hline$>5$ miles & $3.2 \%$ & $3.3 \%$ & & $3.7 \%$ & $4.2 \%$ & \\
\hline \multicolumn{7}{|l|}{ Chronic conditions (\%) } \\
\hline 0 & $12.1 \%$ & $12.2 \%$ & 0.86 & $37.6 \%$ & $37.4 \%$ & 0.51 \\
\hline 1 & $15.4 \%$ & $15.5 \%$ & & $15.7 \%$ & $15.7 \%$ & \\
\hline 2 & $18.8 \%$ & $18.5 \%$ & & $14.7 \%$ & $14.6 \%$ & \\
\hline $3+$ & $53.7 \%$ & $53.8 \%$ & & $32.0 \%$ & $32.3 \%$ & \\
\hline \multicolumn{7}{|l|}{ Hospitalization in 2014} \\
\hline 0 & $74.3 \%$ & $73.6 \%$ & 4.89 & $82.9 \%$ & $81.8 \%$ & 5.54 \\
\hline 1 & $17.3 \%$ & $17.0 \%$ & & $11.7 \%$ & $11.8 \%$ & \\
\hline 2 & $5.1 \%$ & $5.1 \%$ & & $3.4 \%$ & $3.6 \%$ & \\
\hline $3+$ & $3.3 \%$ & $4.3 \%$ & & $2.0 \%$ & $2.8 \%$ & \\
\hline \multicolumn{7}{|l|}{ Provider visit in 2014} \\
\hline Mean $\pm \mathrm{SD}$ & $12.72 \pm 8.28$ & $12.97 \pm 8.80$ & 2.93 & $5.97 \pm 5.84$ & $6.23 \pm 6.22$ & 4.20 \\
\hline \multicolumn{7}{|l|}{ COC in $2014^{*}$} \\
\hline Mean $\pm \mathrm{SD}$ & $0.82 \pm 0.27$ & $0.81 \pm 0.28$ & -4.16 & & & \\
\hline $\mathrm{PCP}$ visit in $2015^{*}$ & & & $t$ test & & & $t$ test \\
\hline Mean $\pm \mathrm{SD}$ & $4.65 \pm 3.84$ & $5.00 \pm 4.48$ & $P=.0003$ & $1.65 \pm 2.37$ & $2.26 \pm 3.32$ & $P<.0001$ \\
\hline \multicolumn{7}{|l|}{ COC in $2015^{*}$} \\
\hline Mean $\pm \mathrm{SD}$ & $0.80 \pm 0.31$ & $0.75 \pm 0.33$ & $P<.001$ & $0.74 \pm 0.37$ & $0.64 \pm 0.40$ & $P<.0001$ \\
\hline $\begin{array}{l}\text { Saw the primary care physician } \\
\text { in } 2015^{*}\end{array}$ & & & $x^{2}$ & & & \\
\hline No & $18.3 \%$ & $21.4 \%$ & $P=.0012$ & & & \\
\hline Yes & $81.7 \%$ & $78.6 \%$ & & & & \\
\hline
\end{tabular}

*Variables were not included in the propensity model.

${ }^{\dagger}$ Seven patients with an identified PCP and retail clinic visit were not within the overlap of propensity score; therefore they were excluded in matched cohort.

${ }^{\ddagger}$ Four patients without an identified PCP and having retail clinic visit were not within the overlap of propensity score; therefore they were excluded in matched cohort.

PCP, primary care physician; SD, standard deviation; COC, Continuity of Care Index. 
Table 3. Comparisons Between Type of Retail Clinic Visit and Continuity of Care for Medicare Beneficiaries in 2015

\begin{tabular}{lccc}
\hline Type of retail clinic visit in 2015* & $\begin{array}{c}\text { Proportion of Patients } \\
\text { Who Saw PCP (\%) }\end{array}$ & $P$-Value & $\begin{array}{c}\text { Continuity of } \\
\text { Care Index }\end{array}$ \\
\hline Chronic condition/preventive care & 72.5 & .012 & $0.68 \pm 0.36$ \\
Simple acute condition & 75.4 & & $0.75 \pm 0.34$ \\
Vaccination & 83.1 & & $0.80 \pm 0.31$ \\
\hline
\end{tabular}

*Single retail clinic visits for multiple complaints were assigned a single visit type designation, according to the highest ranking complaint, as designated by the following hierarchy (highest to lowest): chronic condition/preventive care, simple acute condition, and vaccination. Therefore, patients who received care for chronic conditions/preventive care may have also received care for simple acute conditions or for vaccination in one visit. However, patients who sought retail clinic care for vaccination received only vaccination at that visit, and no other type of care.

PCP, primary care physician.

The type of care sought may be a significant factor contributing to patterns and magnitude of retail clinic use. This is important when considering its impact on continuity of care. In Table 3, we review data regarding the type of visit obtained (chronic/preventive care, simple/acute condition, or vaccination) at a retail clinic by Medicare beneficiaries in the study. A greater proportion $(83.1 \%)$ of beneficiaries who sought care at a retail clinic for vaccination saw their PCP compared with the proportion of those who saw care for simple, acute conditions such as urinary tract infection and upper respiratory tract infection or for chronic conditions and preventive care $(75.4 \%$ and $72.5 \%$, respectively; $P=.012)$. A greater continuity of care (COC) index was also demonstrated in the vaccination group at $0.8(+0.31)$ while the COC for those seeking care for chronic conditions was 0.68 $(+0.36 ; \mathrm{P}=.0002)$.

\section{Discussion}

Our study revealed that in 2015 , retail clinic providers in the Houston metropolitan area were located primarily in Harris County and 3 other suburban counties, and about $75 \%$ were NPs. The geographic distribution is similar to a 2010 study $^{18}$ which found about $88 \%$ of retail clinic locations in urban high-income areas and about $13 \%$ in Health Profession Shortage Areas. ${ }^{18}$ This is concerning given that projections have considered retail clinic expansion as a means to increase health care access for the poor and the uninsured who are at high risk of unplanned ER visits for nonemergent care. ${ }^{18-20}$

Our study population of elderly Medicare beneficiaries had 2.32 retail clinic visits per 1000 persons per month in 2015 , a lower rate than that for the popu- lation aged 18 to 64 years (6.5 retail clinic visits per 1000 persons per month). ${ }^{7}$ Most retail clinic visits were for vaccinations and simple acute infections. However, $10 \%$ of seniors used retail clinic for CDM. Retail clinic users are more likely to be female, White, aged 65 to 74 years of age, and Medicaid ineligible; the reasons for these findings are unclear. However, prior research has shown that women and those aged 66 to 74 years had a greater likelihood of receiving care from NPs. ${ }^{21}$ It is also possible that Medicaideligible beneficiaries reside further away from the retail clinics, $88 \%$ of which are located in urban highincome areas. ${ }^{18}$ Living near a retail clinic was also associated with higher odds of use, a finding similar prior research in working age population. ${ }^{7}$

As expected, sicker seniors visited retail clinic more than healthy seniors. Those with a PCP had lower odds of retail clinic use while those without a PCP were more likely to use retail clinics, mostly for acute illnesses, similar to findings from prior research., ${ }^{3,7,10}$ Among beneficiaries with an identified PCP, the odds of seeing their PCP decreased if they had retail clinic visits. While retail clinic use was lower in the elderly population compared with the younger populations, ${ }^{7}$ our findings of minimal PCP followup raise concern about quality, coordination, and outcome of care among elderly retail clinic users. ${ }^{22,23}$ Prior research has published on the variability and pattern of PCP follow-up rates among retail clinic users. ${ }^{18}$

The finding of $10 \%$ retail clinic visits for CDM was unexpected. Optimal CDM for conditions, such as congestive heart failure, require a stable PCP to establish long-term patient-PCP interpersonal trust, to coordinate care and informational translation across multiple providers for preventive, acute, and chronic care needs. ${ }^{19,24}$ Continuity of care is key to 
health maintenance and the patient centered medical home, especially in Medicare patients with multimorbidity. There is potential for poor outcomes among those using retail clinics for CDM: comprehensive care approaches are less likely in the setting of a walk-in retail clinic visit model. Optimal CDM in elders often requires serial followup of guideline-recommended therapy, tests, medication reconciliation, consultant referrals, and advance directive discussion-tasks not easily accomplished in retail clinics. Our findings of retail clinic association with lower care continuity raise concern for care fragmentation and potential for missed diagnoses due to inadequate test followup, requiring additional health care services, including urgent ER transfer and subsequent hospitalizations. ${ }^{23,25}$

We acknowledge our finding that only $1.3 \%$ Medicare beneficiaries used retail clinics and that among that number, $10 \%$ of visits were for management of chronic conditions. This represents up to $0.13 \%$ of the studied Medicare beneficiaries who sought care at a retail clinic for chronic care management. While this number is small, if we extrapolate our result to the total 58 million Medicare beneficiaries in 2015, this represents nearly 75,400 patients potentially seeking care at retail clinics for chronic care. Overall, the population of Americans aged 65 years and older is expected to substantially increase as baby boomers (those born between 1945 and 1965) reach the age to qualify for Medicare. In addition, retail clinic use is also expected to increase as insurance companies encourage their use over the more expensive care sites such as emergency rooms or urgent care centers. Finally, our study is limited to 1 state and moreover, to 1 metropolitan region, Houston. Majority of care in retail clinics are provided by NPs; however, NP scope of practice in Texas is limited compared with other states in which NPs have autonomy. Thus, we believed the estimated 75,400 patients seeking care at a retail clinic for chronic care management may in fact be underestimated for the entire Medicare population. A national study covering retail clinics in states with different scope of practice regulations for NPs is needed.

Retail clinic use by Medicare beneficiaries will likely grow, so approaches to improve care coordination and communication between retail clinic providers and PCPs are needed. Possible approaches include the development of a visit scoring system to ensure that high-risk patients see their PCP within a week of retail clinic visit, provision of a clinic note record to the patient, informing the patient's PCP via email or text, and implementing integrated, portable, patient-accessible electronic medical records (EMRs) that communicate with other EMRs. Such EMR and care integration may be 1 advantage of the CVS/Aetna merger. The Aetna patient who visits a retail clinic in CVS may have their health data in 1 system. Another suggested approach is the expansion of hospital-based retail clinic models, which allow for easier, more direct access to specialists and other health care services for patients who have chronic disease exacerbations that do not require in-hospital care. ${ }^{27}$

Limitations in our study include the singular focus on older Medicare patients in the Houston metropolitan area and exclusion of HMO patients, thus limiting generalizability of our findings to younger patients or patients with fee-for-service Medicare coverage outside of Houston. The proportion of Medicare patients with both Part A and B coverage under fee-for-service was somewhat lower compared with National Medicare population $(47.0 \%$ vs $54.5 \%)$. Study results are from 2015, and given the recent changes in health care landscape, the results may not necessarily be extrapolated to the current period. We may also have missed some patients who received care at previously operational retail clinics which have since closed. We lack key data on retail clinic practice: social/ functional measures of users, presence of EMR, NP experience, and care quality by $\mathrm{NP}$ versus MDs. These factors may potentially affect access to and quality of retail clinic care.

We acknowledge that patients who visit retail clinics may be referred for further care through emergency rooms and perhaps inpatient hospitalizations. While data exist regarding hospitalizations, cross-sectional analysis does not allow us to tease out timing related to the retail clinic visit (ie, whether a beneficiary was seen in emergency room/ hospital before or after retail clinic visit). Further studies would benefit from longitudinal analysis over many years and of additional US states to enable review of longitudinal patterns and to ensure validity of any associations.

Nevertheless, our findings have health care policy implications, given the rapid rise in retail clinic use and the potential for care fragmentation in clinically complex elderly Medicare users. Primary care discontinuity among elderly retail clinic users in our study underscore the need for better systems to improve integration and coordination of retail 
clinic care. Such systems are key to reducing hospital, ER visits, and health care costs. Our findings also highlight the need for long-term national studies of the impact of retail clinic use and uncoordinated care or "visit entropy" on rehospitalizations and other outcomes that matter to clinically complex elders. ${ }^{28}$ Data from such studies can guide policy makers, health system leaders and clinicians on ways to improve quality and continuity of care among retail clinic users.

To see this article online, please go to: http://jabfm.org/content/ 32/4/531.full.

\section{References}

1. Bohmer R. The rise of in-store clinics-Threat or opportunity? N Engl J Med 2007;356:765-658.

2. Charland T. Calm before the storm. Merchant medicine-The ConvUrgentCare Report: U.S. Walk-In Clinic Market Report 2018;11:1-5.

3. Mehrotra A, Wang MC, Lave JR, et al. A comparison of patient visits to retail clinics. Primary care physicians, and emergency departments. Health Aff 2008;27:1272-1282.

4. Mehrotra A, Lave JR. Visits To retail clinics grew fourfold from 2007 to 2009 although their share of overall outpatient visits remains low. Health Aff 2012;31:2123-2129.

5. Ahme A, Fincham JE. Physician office vs retail clinic: Patient preferences in care seeking for minor illnesses. Ann Fam Med 2010;8:117-123.

6. National Conference of State Legislatures. Retail health clinics: State legislation and laws. Available from: www.ncsl.org/research/health/retail-healthclinics-state-legislation-and-laws.aspx. Accessed Mar 25, 2018.

7. Ashwood JS, Reid RO, Setodji CM, et al. Trends in retail clinic use among the commercially insured. Am J Manag Care 2011;17:e443-e448.

8. Frakt AB, Garthwaite C. The CVS-Aetna Merger: Another large best on the changing US health care landscape. Ann Intern Med 2018;168:511-512.

9. Walmart in talks to strengthen ties to health insurer Humana. Available from: https://www.nytimes.com/ 2018/03/30/business/walmart-humana-merger.html Accessed March 31, 2018.

10. Mehrotra A, Liu H, Adams JL, et al. Comparing costs and quality of care at retail clinics with that of other medical setting for 3 common illnesses. Ann Intern Med 2009;151:321-328.

11. Reid RO, Ashwood JS, Friedberg MW, et al. Retail clinic visits and receipt of primary care. J Gen Intern Med 2013;28:504-512.

12. Hussey PS, Schneider EC, Rudin RS, et al. Continuity and the costs of care for chronic disease. JAMA Intern Med 2014;174:742-748.
13. Goodman RA, Posner SF, Huang ES, et al. defining and measuring chronic conditions: Imperatives for research, policy, program, and practice. Prev Chronic Dis 2013;10:120239.

14. Shah BR, Hux JE, Laupacis A, et al. Administrative data algorithms can describe ambulatory physician utilization. Health Serv Res 2007;42:1783-1796.

15. Pollack CE, Hussey PS, Rudin RS, et al. Measuring care continuity: A comparison of claims-based methods. Med Care 2016;54:e30-e34.

16. Parsons L. Reducing bias in a propensity score matched-pair sample using greedy matching techniques. SAS Users Group International Conference, Long Beach, CA, 2001.

17. Austin PC. A Tutorial and case study in propensity score analysis: An application to estimating the effect of in-hospital smoking cessation counseling on mortality. Multivariate Behav Res 2011;46:119-151.

18. Rudavsky R, Mehrotra A. Sociodemographic characteristics of communities served by retail clinics. J Am Board Fam Med 2010;23:42-48.

19. Gulliford M, Cowie L, Morgan M. Relational and management continuity survey in patients with multiple long-term conditions. J Health Serv Res Policy 2011;16:67-74.

20. Rohrer JE, Angstman KB, Garrison GM, et al. Family medicine patients who use retail clinics have lower continuity of care. J Primary Care Comm Health 2013;4:150-153.

21. Xue Y, Goodwin JS, Adhikari D, et al. Trends in primary care provision to medicare beneficiaries by physicians, nurse practitioners, or physician assistants: 2008-14. J Prim Care Community Health 2017;8:256-263.

22. Pollack CE, Armstrong K. The geographic accessibility of retail clinics for underserved populations. Arch Intern Med 2009;169:945-949; discussion 950-953.

23. Ashwood JS, Gaynor M, Setodji CM, et al. Retail clinic visits for low-acuity conditions increase utilization and spending. Health Aff (Millwood) 2016;35:449-455.

24. Hill KM, Twiddy M, Hewison J, et al. Measuring patient-perceived continuity of care for patients with long-term conditions in primary care. BMC Fam Pract 2014;15:191.

25. Zitek T, Tanone I, Ramos A, et al. Most transfers from urgent care centers to emergency departments are discharged and many are unnecessary. J Emerg Med 2018;54:882-888.

26. Creditor MC. Hazards of hospitalization of the elderly. Ann Intern Med 1993;118:219-223.

27. Kaissi A, Charland TA. How satisfied are hospital systems with their ownership of retail clinics? J Healthcare Manag 2013;58:143-153.

28. Garrison GM, Keuseman R, Bania B, et al. Visit entropy associated with hospital readmission rates. J Am Board Fam Med 2017;30:63-70. 